10. Коробова Т.М. Развитие интеллектуальных способностей учащихся основной школы при обучении физике: дис. ... канд. пед. наук. М., 2008. 225 с.

11. Борисова Ю.В. Дифференциация обучения физике на основе учета когнитивных стилей учащихся: дис. ... канд. пед. наук. М., 2004.

12. Третьякова С.В. Естественнонаучные проекты как средство формирования учебно-информационных умений у учащихся при обучении физике: дис. ... канд. пед. наук. М., 2004.

13. Харитонов А.Ю. Формирование информационной культуры учащихся основной школы в процессе обучения физике: дис. ... канд. пед. наук. Самара, 2000.

14. Степин В.С. Саморазвивающиеся системы и философия синергетики // Экономические стратегии. 2009. №7. C. 24-35.
15. Кондаков В.А. Дидактические основы построения учебных систем знания по физике. Лекции по спецкурсу. Куйбышев: КГПИ, 1977. 47 с.

16. Кондаков В.А. Строение и свойства вещества. Пособие для учителя. М.: Просвещение, 1970. 151 с.

17. Прангишвили И.В. Энтропийные и другие системные закономерности: Вопросы управления сложными системами. М.: Наука, 2003. 428 с.

18. Маслоу А. Новые рубежи человеческой природы. М.: Смысл, 1999. 425 с.

19. Самойлов Е.А. Управление интеллектуальным развитием школьников при обучении физике в класcax физико-математического профиля: монография. Самара: Изд-во ПГСГА, 2013. 452 с.

20. Холодная М.А. Психология интеллекта: парадоксы исследования. 2-е изд., перераб. и доп. СПб.: Питер, 2002. 272 с.

\title{
TEACHING PROSPECTIVE TEACHERS OF PHYSICS HOW TO CONTROL THE INTELLECTUAL DEVELOPMENT OF SCHOOLCHILDREN PROCEDURALLY
} (C) 2017

Samoylov Evgeny Andreevich, doctor of pedagogical sciences, professor of Physics, Mathematics and Teaching Methods Department Samara State University of Social Sciences and Education (Samara, Russian Federation)

Abstract. The article analyzes the different approaches to the control of the intellectual development of students in teaching physics in school, due on the one hand, to the diversity of psychological interpretations of intelligence and models of its formation and, on the other hand, used in the study, methodological orientations (classical, no classical, or postnonclassical). A description of the procedural model is proposed by the author, it shows how to control the intellectual development of students, which is built in accordance with the type of post-nonclassical rationality based on a holistic (holistic) understanding of the nature of intelligence, taking into account the value of the information society and the influence of the disciples of the collective on the effectiveness of individual educational activities for teaching physics. The proposed procedural model allows to develop recommendations for effective adaptive learning physics students, taking into account the laws of intellectual development and the specificity of operation holonic organizational systems. From a procedural point of view controlling the intellectual development of students is a regulation of consistent educational change states of inhomogeneous collective of students, which leads to the desired enrichment of the intellectual resources of each school-nick for Learning Physics. The approach of controlling the intellectual development of students, described by the author, is the subject of study by students - future teachers of physics - in the framework of forming pedagogical experiment in Samara State University of Social Sciences and Education.

Keywords: intellect; control of individual intellectual development in teaching physics; developing a collective entity; procedural control model intellectual development of students.

УДК 378.046 .4

\section{ОСОБЕННОСТИ ФОРМИРОВАНИЯ ОБЩЕКУЛЬТУРНЫХ КОМПЕТЕНЦИЙ БАКАЛАВРОВ ПРОФИЛЯ «ФИЗИЧЕСКАЯ КУЛЬТУРА И СПОРТ»}

(C) 2017

Серпер Сергей Александрович, кандидат экономических наук, докторант СГСПУ

Буранок Олег Михайлович, доктор педагогических наук, доктор филологических наук, профессор, заведующий кафедрой русской, зарубежной литературы и методики преподавания литературы

Самарский государственный соииально-педагогический университет (2. Самара, Российская Федераиия)

Аннотация. В статье рассматривается специфика формирования общекультурных компетенций студентов профиля «Физическая культура и спорт». Федеральный государственный образовательный стандарт третьего поколения, утверждённый Министерством образования и науки Российской Федерации, предполагает формирование у студентов направления «Физическая культура и спорт» общекультурных компетенций, важных при реализации программы развития личности современного специалиста и тренера. Значение общекультурных компетенций в системе современного образования увеличивается и в связи с установлением личностноориентированной парадигмы образования, при которой социуму требуются самостоятельные, активные, способные к саморазвитию и самообразованию профессионалы, особенно в областях, жизненно важных для развития российского общества и государства. В статье показано, что развитие фитнеса сформировало такой вопрос, как педагогика фитнеса: необходимо определить не только набор профессиональных и общекуль- 
турных компетенций, содержание и структуру учебных планов для будущих профессионалов в сфере фитнеca, но и то, какие общекультурные компетенции и каким образом способствуют формированию будущих специалистов по фитнесу, как взаимодействуют профессиональные и общекультурные компетенции в ходе учебного процесса. Решение этого вопроса позволит наиболее оптимально и эффективно реформировать систему подготовки специалистов по физической культуре и поможет реализовать государственные задачи по сохранению здоровья нации.

Ключевые слова: общекультурные компетенции; высшее образование; бакалавриат; физическая культура и спорт; подготовка бакалавров; педагогическое образование; личностно-ориентированная парадигма образования; педагогика фитнеса; профессиональные компетенции; учебный процесс; здоровьесбережение.

Модернизация социально-экономической и образовательной сфер России, происходящая на фоне развития международных контактов, переориентация общественных ценностей и приоритетов всё больше усиливают потребность в комплексном решении задач, стоящих перед высшей школой, перед российским обществом, перед государством. Две задачи для российского образования имеют особый приоритет, отражённый как в Федеральных государственных образовательных стандартах, так и в программных документах российского правительства. Это, с одной стороны, углубление социокультурной функции образования через формирование в каждой группе специальностей набора общекультурных компетенций. А с другой стороны, реализация политики здоровьесбережения нации, формирования культуры здорового образа жизни у будущих специалистов. Представляется возможным и нужным создание концепции новой системы формирования общекультурных компетенций у студентов профиля «Физическая культура», сочетающей в себе необходимость гуманизации образования и отвечающей требованиям государственной политики в области физкультуры и спорта.

Изучение теоретико-методологических основ формирования общекультурных компетенций у будущих специалистов по физической культуре целесообразно начать с определения роли и функций общекультурных компетенций в образовательном процессе.

Федеральный государственный образовательный стандарт третьего поколения, утверждённый Министерством образования и науки Российской Федерации [1], предполагает формирование у студентов направления «Физическая культура и спорт» общекультурных компетенций, важных при реализации программы развития личности современного специалиста и тренера.

Компетенция - это важнейшая категория современной педагогики, подлинный стержень, на котором держится система образования, а совершенствование методик формирования компетенций - одна из приоритетных задач современной науки [2, с. $19 ; 3$, c. $159 ; 4$, с. 926]. Как способность использовать полученные знания и навыки в профессиональной деятельности, компетенция тесно связана с набором дисциплин, отвечающих за формирование той или иной компетенции.

Ведущие направления функционирования высшей школы в контексте гуманитаризации физического образования и создания социокультурных условий для профессиональной реализации студентов подразумевают формирование предпосылок для сбалансированного развития личности будущего тренера, осо- бенно в областях, касающихся его прямой профессиональной деятельности [5, с. 124-131; 6, с. 24-25].

Как правило, исследователи сходятся на мнении, что формирование общекультурных компетенций это, главным образом, функция гуманитарных дисциплин федерального и регионального компонентов [7, с. 145]. В период реформирования высшей школы неизменно подчёркивалось, что дисциплины гуманитарного блока важны не только для формирования коммуникативной и информационной культуры, общегуманитарных ценностей, гуманистического взгляда на мир, но и для более эффективной реализации профессиональных компетенций [2, с. 20].

Согласно исследованиям В.П. Бездухова, С.Е. Мишиной, О.В. Правдиной, А.А. Петрова [8; 9; 10, c. 253], общекультурные компетенции обусловливают продуктивную деятельность не только в профессиональной сфере (наравне с профессиональными компетенциями), но и позволяют выпускнику наиболее оптимальным образом адаптироваться в социокультурной среде. Для бакалавра профиля «Физическая культура и спорт» это означает формирование способности взаимодействия с людьми, их толерантному пониманию, что при работе фитнес-тренером чрезвычайно необходимо.

Значение общекультурных компетенций в системе современного образования увеличивается и в связи с установлением личностно-ориентированной парадигмы образования, при которой социуму требуются самостоятельные, активные, способные к саморазвитию и самообразованию профессионалы, особенно в областях, жизненно важных для развития российского общества и государства, одной из которых является политика здоровьесбережения нации.

В государственных стандартах и научно-педагогических работах выделены два больших блока компетенций: общекультурные и профессиональные (исследования А.Г. Бермуса, А.В. Хуторского, Дж. Равена) $[11 ; 12]$, которые, в свою очередь, содержат три основных составляющих: гносеологическую, личностную, деятельностную [13, с. 10-19]. В гносеологическую составляющую общекультурной компетенции входят традиционно выделяемые знания, умения, навыки; основой личностной составляющей является восприятие и рефлексия по полученным знаниям, умениям, навыкам; деятельностный элемент компетенций связан с практической реализацией приобретённого опыта.

При формировании общекультурной компетенции будущих специалистов по физической культуре необходимо, чтобы все три составляющие взаимодействовали в процессе формирования не только между собой, но и с набором профессиональных компетенций, которые студент осваивает во время 
обучения. Это в конечном счёте призвано и реализовать государственный стандарт, и оптимально подготовить студентов к современным формам профессиональной реализации (что для преподавателя физкультуры, тренера имеет первостепенную важность), и решить приоритетную государственную задачу по формированию здоровой нации.

Это довольно непростая задача, так как современная система высшего образования, где формируется комплекс общекультурных компетенций бакалавров и магистров, находится в процессе реформирования, изменения государственных стандартов, переподготовки профессиональных кадров, - это вносит неминуемые коррективы, и политика сохранения здоровья часто отходит на второй план [14, c. 34-38].

Кроме того, современные педагогические методы и приёмы не всегда нацелены на формирование общекультурных компетенций бакалавров по физической культуре и спорту с учётом профилей специальностей и особенностей будущей профессиональной деятельности.

Изучение исследовательских концепций показало, что существует несколько подходов к определению понятия «общекультурная компетенция» [15, c. 353]. Однако учёные сходятся во мнении, что общекультурные компетенции, независимо от подхода к их определению, создают базовую основу для формирования всего комплекса профессиональных компетенций, а также предоставляют жизненные ориентиры для эффективного взаимодействия человека и социума, человека и природы [16, с. 120].

Исследования показывают, что невнимание к формированию общекультурной компетенции препятствует профессиональному и личностному развитию выпускников, негативно воздействует на эффективность всей системы высшего образования, что, в свою очередь, негативно сказывается на выполнении государственных задач в области политики здорового образа жизни. Поэтому формирование общекультурной компетентности как интегративного качества личности, определяющего личностный рост студентов и способствующего совершенствованию образовательного процесса в вузе, приобретает особую значимость.

Длительный процесс формирования общекультурных компетенций бакалавров в педагогическом вузе в общих чертах обозначен в государственном стандарте нового поколения и в учебных, рабочих программах по дисциплинам профиля «Физическая культура и спорт».

Формулировки общекультурных компетенций и их связь с конкретными учебными дисциплинами в рамках обозначенного направления представляют значительное исследовательское поле как в практическом, так и в теоретическом плане, позволяют педагогу оптимизировать процесс формирования компетенций.

Современный федеральный стандарт предполагает по направлению «Педагогическое образование» (профиль «Физическая культура и спорт») формирование у выпускника бакалавра девяти общекультурных компетенций:

- способность использовать основы философских и социогуманитарных знаний для формирования научного мировоззрения (ОК-1);
- способность анализировать основные этапы и закономерности исторического развития общества для формирования гражданской позиции (ОК-2);

- способность использовать основы экономических знаний в различных сферах жизнедеятельности (OK-3);

- способность использовать основы правовых знаний в различных сферах жизнедеятельности (ОК-4);

- способность к коммуникации в устной и письменной формах на русском и иностранном языках для решения задач межличностного и межкультурного взаимодействия (ОК-5);

- способность работать в коллективе, толерантно воспринимать социальные, этнические, конфессиональные и культурные различия (ОК-6);

- способность к самоорганизации и самообразованию (ОК-7);

- готовность поддерживать уровень физической подготовки, обеспечивающий полноценную деятельность (ОК-8);

- способность использовать приемы первой помощи, методы защиты в условиях чрезвычайных ситуаций (ОК-9) [1].

Часть данных компетенций формируется на предметах гуманитарного цикла, часть - естественнонаучными дисциплинами, но некоторые ОК из этого перечня могут и должны формироваться в процессе профессиональной подготовки бакалавров профиля «Физическая культура и спорт». В этом плане затрагивается достаточно сложный вопрос: как функционирует и как должен функционировать механизм формирования общекультурных компетенций бакалавров на дисциплинах, напрямую связанных с будущей профессиональной деятельностью.

Важно подчеркнуть, что от налаженной, системной связи процесса формирования общекультурных и профессиональных компетенций зависит качество деятельности будущего специалиста, качество образования в вузе, качество и эффективность реализации задачи по здоровьесбережению нации.

Прежде всего, необходимо рассмотреть, каким образом данный вопрос решён в уже существующих программах по профилю «Физическая культура и спорт» Самарского государственного социальнопедагогического университета. Выделяется сразу несколько программ учебных дисциплин, которые учитывают возможность формирования общекультурных компетенций не в ущерб профессиональным. Так, дисциплина «Теория и методика обучения предмету "Физическая культура"» предполагает, что в ходе её изучения у студентов будут сформированы две общекультурные компетенции (в соответствии со стандартом ФГОС 3+): способность использовать основы философских и социогуманитарных знаний для формирования научного мировоззрения (ОК-1); готовность поддерживать уровень физической подготовки, обеспечивающий полноценную деятельность (ОК-8) [17].

Представляется, что для будущего тренера, специалиста по физической культуре и спорту ОК-1 имеет несколько большее значение, чем это подчёркивается в научной литературе. Выпускник должен получить способность не только использовать философские концепции для формирования научного мировоззрения, но и иметь достаточно полные пред- 
ставления о том, как некоторые из данных концепций связаны с его профессиональной деятельностью. Особенно это важно при современном развитии сферы фитнес-индустрии и поддержания здорового образа жизни (где трудоустраивается значительное число выпускников направления «Физическая культура и спорт»), когда в каждом городе России появились программы по фитнес-йоге [18]. Выпускник должен разбираться как в философской, так и в практической составляющей данных учений, чтобы избежать трудоустройства в непрофессиональные компании, возникшие под влиянием конъюнктурных соображений и моды. И формирование такого рода знаний подразумевает ОК-1. Причём возможно, что философские знания об особенностях йоги могут формироваться на таких дисциплинах, как «История», «Философия», «Религиоведение», тогда как и практические, и философские потенциально можно сформировать на специальных дисциплинах или отдельных спецкурсах.

ОК-8 («готовность поддерживать уровень физической подготовки, обеспечивающий полноценную деятельность») является для бакалавров профиля «Физическая культура и спорт», в прямом смысле, профессиональной компетенцией, формирование которой происходит практически на всех предметах профессионального цикла подготовки.

Комплекс сформированных указанных компетенций позволит выпускнику более эффективно реализовать себя в профессиональной сфере, в том числе в такой востребованной и быстро развивающейся, как фитнес-индустрия.

Масштабные социально-экономические перемены в Российской Федерации, начиная с 1990-х годов, способствовали быстрому развитию фитнес-сферы $[19$, с. $74 ; 20]$. Это вызвало нарастающую потребность в профессиональных кадрах в данной области и определило существенную востребованность специалистов для фитнеса. Следовательно, развитие фитнеса сформировало такой вопрос, как педагогика фитнеса: необходимо определить не только набор профессиональных компетенций, содержание и структуру учебных планов для будущих профессионалов в сфере фитнеса, но и то, какие общекультурные компетенции и каким образом способствуют формированию будущих специалистов по фитнесу, как взаимодействуют профессиональные и общекультурные компетенции в ходе учебного процесса, а главное - как наиболее оптимально и эффективно реформирование системы подготовки специалистов по физической культуре поможет решить задачи, поставленные в «Стратегии развития физической культуры и спорта в Российской Федерации на период до 2020 года».

\section{СПИСОК ЛИТЕРАТУРЫ:}

1. Федеральные государственные образовательные стандарты 3 поколения // http://fgosvo.ru/ uploadfiles/fgosvob/440301.pdf.

2. Троянская С.Л. Общекультурная компетентность: опыт определения и структурирования // Культурно-историческая психология. 2008. № 2. C. 19-23.

3. Васильева И.В. Общекультурные и социальноличностные компетенции выпускника вуза // Российский научный журнал. 2011. № 21. С. 158-163.
4. Гатина А.Р. Общекультурные компетенции в становлении будущего педагога // В мире научных открытий. 2014. № 11.2 (59). С. 924-929.

5. Леонова Е.В. Формирование общекультурных компетенций у студентов технического вуза // Высшее образование в России. 2010. № 2. С. 124-131.

6. Синякова М.Г. Основные подходы к определению сущности общекультурной компетентности бакалавра менеджмента // Международный журнал экспериментального образования. 2010. № 9. С. 24-25.

7. Сидорова Т.Л. Общекультурные компетенции и культура речи // Primo Aspectu. 2012. Т. 10. № 3 (90). С. 145.

8. Бездухов В.П., Мишина С.Е., Правдина О.В. Теоретические проблемы становления педагогической компетентности учителя. Самара: СГСПУ, 2001. $132 \mathrm{c}$.

9. Петров А.А. Общекультурная компетенция учителя и ее влияние на успешность педагогической деятельности: автореф. дис. ... канд. пед. наук. Пенза, 1999. $16 \mathrm{c.}$

10. Лобанова А.А. Общекультурные компетенции старшеклассников // Российский научный журнал. 2012. № 27. C. 253-256.

11. Бермус А.Г. Проблемы и перспективы реализации компетентностного подхода в образовании [Электронный ресурс] // Эйдос: Интернет-журнал. 2005. 10 сентября. - http://eidos.ru/journal/2005/091012.htm.

12. Равен Дж. Компетентность в современном обществе. Выявление, развитие и реализация. М.: ACT, 2002. $396 \mathrm{c}$.

13. Зимняя И.А. Социально-профессиональная компетентность как целостный результат профессионального образования // Актуальные проблемы качества образования и пути их решения в контексте европейских и мировых тенденций: мат-лы XV всерос. науч.-метод. конф. М., 2005. С. 10-19.

14. Зимняя И.А. Ключевые компетентности - новая парадигма результата образования // Высшее образование сегодня. 2003. № 5. С. 34-42.

15. Абызов А.Г. Общекультурные компетенции в деятельности выпускника университета // Роль образования в формировании экономической, социальной и правовой культуры: Сборник научных трудов. СПб.: Комитет по науке и высшей школе Правительства Санкт-Петербурга, 2014. С. 353-357.

16. Викулина М.А. Общекультурные компетенции - основа педагогики современного специалиста // Вестник ТГПУ. 2015. № 12 (165). С. 120.

17. Основные образовательные программы [Электронный ресурс] // Официальный сайт СГСПУ. http://pgsga.ru/academy/structure/administration/ex_serv /educational-and-methodical/the_basic_educational_ programs.

18. Уколова И.В. Социологические аспекты фитнес-движения в России // Вестник Волжского университета им. В.Н. Татищева. 2009. № 3. С. 251-261.

19. Соколова О.В., Соколова М.Л. Физическая культура и спорт в студенческой среде // Известия Тульского государственного университета. Физическая культура. Спорт. 2015. № 3. С. 73-76.

20. Традиции и инновации российского высшего образования в сфере физической культуры: опыт транскультурного ориентирования: монография / под ред. Е.В. Утишевой, Н.Г. Закревской. СПб.: Стратегия будущего, 2011. 274 с. 


\section{FEATURES OF COMMON CULTURAL COMPETENCE DEVELOPMENT AT BACHELORS MAJORING IN «PHYSICAL CULTURE AND SPORT»}

(C) 2017

Serper Sergey Aleksandrovich, candidate of economical sciences, doctoral candidate of SSUSSE

Buranok Oleg Mikhailovich, doctor of philological sciences, doctor of pedagogical sciences, professor, head of Russian Literature, Foreign Literature and Methods of Teaching Literature Department

Samara State University of Social Sciences and Education (Samara, Russian Federation)

Abstract. The paper deals with features of common cultural competence development at bachelors majoring in «Physical culture and sport». The federal state educational standard of the third generation, approved by the Ministry of Education and Science of the Russian Federation, involves common cultural competence development at bachelors majoring in «Physical Culture and Sports». This competence is important for the implementation of the program that develops a modern expert and trainer's personality. The value of common cultural competence in the system of modern education is increasing due to the personality-oriented education paradigm establishment when the society requires active, capable of self-development and self-education professionals, especially in areas that are vital for the development of the Russian society and the state. The paper shows that the development of fitness has formed a fitness pedagogy: it is necessary to determine a set of professional and general cultural competence, content and curriculum framework for future professionals in the field of fitness as well as what common cultural competence contribute to the training of future experts in fitness and how professional and general cultural competence interact in the educational process. Solving this problem will allow to reform the system of experts' training and will help to achieve national objective to preserve the nation's health.

Keywords: common cultural competence; higher education; bachelor's degree; physical culture and sport; training of bachelor's; pedagogical education; personality-oriented education paradigm; fitness pedagogy; professional competence; educational process; health care.

УДК 373.5.016: 51: 81’246.2 (571.56)

\section{ОСОБЕННОСТИ ФОРМИРОВАНИЯ У ШКОЛЬНИКОВ МАТЕМАТИЧЕСКИХ ПОНЯТИЙ НА ОСНОВЕ БИЛИНГВАЛЬНОГО ОБУЧЕНИЯ}

(C) 2017

Спиридонова Наталья Ивановна, научный сотрудник

Институт национальных школ Республики Саха (Якутия) (г. Якутск, Российская Федерациия)

Аннотащия. В статье рассматривается процесс формирования математических понятий у школьников в условиях билингвального (двуязычного) обучения. Описываются результаты экспериментальной работы, включающей анкетирование учащихся и учителей, направленной на выявление предпочтения родного или русского языка как языка обучения, проверочную работу по выявлению уровня сформированности математического языка у учащихся 5-6 классов на основе двух языков. В результате анализа психологопедагогической и учебно-методической литературы, содержания диссертационных работ по теме исследования выявлены особенности организации билингвального образовательного процесса по формированию математических понятий в образовательных организациях Республики Саха (Якутия), который протекает поэтапно и реализуется посредством совокупности учебных действий. Определено, что основным средством выполнения действий, соответствующих этапам формирования математических понятий, может являться билингвальный дидактический комплекс, направленный на формирование понятий и развитие математической речи учащихся. Полученные в ходе исследования материалы могут быть положены в основу проектирования методики формирования математических понятий в условиях двуязычия, создания учебнометодической литературы, а также использованы учителями школ с родным языком обучения.

Ключевые слова: билингвальное образование; государственный язык; математическая грамотность; математическая речь; математический язык; математическое понятие; методика формирования понятий; модели билингвального обучения; Республика Саха (Якутия); родной язык; этапы формирования математических понятий; язык обучения.

На современном этапе развития российского образования возросла роль человеческого капитала, который является одним из ключевых факторов развития общества, экономики и государства. Как отмечено в Концепции федеральной целевой программы развития образования на 2016-2020 годы, формирование конкурентоспособной личности является основной задачей современной школы. Умение использовать полученные знания и навыки в решении жизненных проблем определяют эффективность образования и характеризуют учащегося как конкурен- тоспособную личность. В мониторинговых исследованиях Международной программы по оценке образовательных достижений учащихся PISA (Programme for International Student Assessment) приводится оценка способности пятнадцатилетних школьников применять в реальной жизни знания, полученные в школе, которая определяется по трем параметрам: грамотность чтения, математическая грамотность, естественнонаучная грамотность. В этих исследованиях под математической грамотностью понимают «способность индивидуума формулировать, приме- 